Tropical Journal of Pharmaceutical Research July 2019; 18 (7): 1487-1492

ISSN: 1596-5996 (print); 1596-9827 (electronic)

(1) Pharmacotherapy Group, Faculty of Pharmacy, University of Benin, Benin City, 300001 Nigeria.

\title{
Trichlorophenyl-benzoxime induces apoptosis in human colon carcinoma cells via activation of mitochondria- dependent pathway
}

\author{
Zhongfu Xiao', Ke Zhang ${ }^{2}$, Yun Huang ${ }^{2}$, Yufan Zhou ${ }^{2}$, Kuan $\mathrm{Hu}^{2 *}$ \\ ${ }^{1}$ Department of Anesthesiology, ${ }^{2}$ Department of General Surgery, Xiang Ya Hospital, Central South University, Changsha, \\ Hunan 410008, China
}

*For correspondence: Email: KennithKeithjzt@yahoo.com; Tel: 0086-0731-84327191

\begin{abstract}
Purpose: To determine the apoptotic effect of trichlorophenyl-benzoxime (TCPB) on colorectal cancer (CRC) cells, and to elucidate the mechanism of action.

Methods: Colon carcinoma cell lines (DLD-1 and HT-29) were used in this study. The cells were cultured in Dulbecco's modified Eagle's medium (DMEM) supplemented with $10 \%$ fetal bovine serum (FBS) and $1 \%$ penicillin/streptomycin at $37{ }^{\circ} \mathrm{C}$ in an atmosphere of $5 \% \mathrm{CO}_{2}$ and $95 \%$ air. When the cells attained $60-70 \%$ confluency, they were treated with serum-free medium and graded concentrations of TCPB $(1.0-6.0 \mu \mathrm{M})$ for $24 \mathrm{~h}$. Cell viability and apoptosis were assessed using 3-(4, 5-dimethylthiazol-2-yl) 2, 5-diphenyltetrazolium bromide (MTT) and flow cytometric assays, respectively. Western blotting and 2', 7' dichlorofluorescein diacetate (DCFH DA) assays were used for the determination of expression levels of apoptotic proteins, and levels of reactive oxygen species (ROS), respectively.

Results: Treatment of DLD-1 and HT-29 cells with TCPB led to significant and dose-dependent reductions in their viability, as well as significant and dose-dependent increases in the number of apoptotic cells $(p<0.05)$. Treatment of HT-29 cells with TCPB led to significant increases in the population of cells in the G0/G1 phase, but significant reduction of cell proportion in $S$ and G2/M phases $(p<0.05)$. It also significantly and dose-dependently upregulated the expressions of caspase-3 and bax, down-regulation of the expression of $\mathrm{bcl}-2(p<0.05)$. TCPB treatment upregulated the expressions of p53, cytochrome $c$ (cyt c), procaspase-3, and procaspase-9, but down-regulated the expression of $p$ Akt dose-dependently $(p<0.05)$. The expression of Akt in HT-29 cells was not significantly affected by TCPB $(p>0.05)$. However, TCPB significantly enhanced the cleavage of PARP1, and significantly and dose-dependently increased the levels of ROS in HT-29 cells $(p<0.05)$.

Conclusion: These results suggest that TCPB exerts apoptotic effect on CRC cells via activation of mitochondria-dependent pathway, and thus can be suitably developed for the management of colon cancer.
\end{abstract}

Keywords: Colorectal cancer, Trichlorophenyl-benzoxime, Mitochondrial pathway, Apoptosis

\begin{abstract}
This is an Open Access article that uses a fund-ing model which does not charge readers or their institutions for access and distributed under the terms of the Creative Commons Attribution License (http://creativecommons.org/licenses/by/4.0) and the Budapest Open Access Initiative (http://www.budapestopenaccessinitiative.org/read), which permit unrestricted use, distribution, and reproduction in any medium, provided the original work is properly credited.
\end{abstract}

Tropical Journal of Pharmaceutical Research is indexed by Science Citation Index (SciSearch), Scopus, International Pharmaceutical Abstract, Chemical Abstracts, Embase, Index Copernicus, EBSCO, African Index Medicus, JournalSeek, Journal Citation Reports/Science Edition, Directory of Open Access Journals (DOAJ), African Journal Online, Bioline International, Open-J-Gate and Pharmacy Abstracts 


\section{INTRODUCTION}

Colorectal cancer (CRC) is the third most common cancer of the gastrointestinal tract (GIT), and one of the most frequently diagnosed malignancies of the intestines [1,2]. It is one of the leading causes of early mortality in developed nations [1,2]. In Asia, the incidence of CRC has greatly increased due to a shift to Western-type diets, changing environment, and lifestyle modification [3]. The disease is characterised by insidious onset which makes its diagnosis difficult [3]. In more than $35 \%$ of patients with CRC, diagnosis is made at the late stage of the disease [4]. Colorectal cancer metastasises very quickly and its recurrence usually occurs within 5 years post-surgery [4]. Surgery and adjuvant chemotherapy are the two common strategies for treating CRC. Development of resistance remains the major factor responsible for poor prognosis of CRC [5].

Apoptosis is programmed cell death which occurs in multicellular organisms [6,7]. The apoptotic process is characterised by changes in cell morphology such as blebbing of the plasma membrane, cell shrinkage, altered mitochondrial membrane potential, and condensation and cleavage of chromatin [6,7]. Cell apoptosis is generally regulated by two pathways: extrinsic and intrinsic pathways [8]. Death receptors on surfaces of cells are involved in the induction of apoptosis via the extrinsic pathway [9]. These surface receptors elicit their effects by activating and upregulating the expression of caspase-8 [9]. In contrast, the intrinsic pathway of apoptosis involves several stress stimuli which change the level of bcl-2 protein resulting in the release of cytochrome $c$ from mitochondria. In addition, Smac and Apaf-1 are also released from the mitochondria under the influence of bcl-2 protein overexpression, which together with cytochrome $c$ catalyse the activation of caspases 3 and 9 [9]. The anticancer activity of most chemotherapeutic agents is exerted via induction of apoptosis [10].

Compounds of natural origin have been investigated for their cytotoxicity against different types of carcinoma cells [11]. Indeed, compounds containing flavonoid scaffold have been shown to effectively inhibit the proliferation of various types of carcinoma such as pulmonary, breast and prostate cancers [12]. It has been reported that flavonoid-bearing compounds are generally less toxic, and this makes them suitable candidates for the development of potential anticancer drugs [12]. The present study investigated the apoptotic effect of TCPB on CRC cells, and the underlying mechanism.

\section{EXPERIMENTAL}

\section{Materials}

Dulbecco's modified Eagle's medium (DMEM) and MTT solution were products of Sigma-Aldrich (USA). Fetal bovine serum (FBS) and Applied Biosystems 7300 RT- PCR machine were products of Life Technologies (USA). Polyvinylidene fluoride membranes, chemiluminescence $(E C L)$ kit and autoradiography film were purchased from Millipore Co. Ltd (USA), while RNase A was a product of Nanjing KeyGen Biotech Co., Ltd. Flow cytometer was obtained from BD Biosciences (USA).

\section{Cell lines and culture}

Colon carcinoma cell lines (DLD-1 and HT-29) were obtained from the Academia Sinica (China). The cells were cultured in DMEM supplemented with $10 \%$ FBS and $1 \%$ penicillin/streptomycin at $37{ }^{\circ} \mathrm{C}$ in an atmosphere of $5 \% \mathrm{CO}_{2}$ and $95 \%$ air. When the cells attained $60-70 \%$ confluency, they were treated with serum-free medium and graded concentrations of TCPB for $24 \mathrm{~h}$. Cells in logarithmic growth phase were selected and used in this study.

\section{Assessment of cell viability}

The viability of the cells in the presence of TCPB was assessed using MTT assay. The cells $(3 x$ $10^{5}$ cells/well) were seeded in 96-well plates and cultured in DMEM for $24 \mathrm{~h}$. Then, TCPB $(1.0-6.0$ $\mu \mathrm{M})$ was added to the cells and incubated for 72 h. At the end of the third day, $20 \mu \mathrm{L}$ of $5 \mathrm{mg} / \mathrm{mL}$ MTT solution was added to the wells, followed by incubation for another $4 \mathrm{~h}$. The medium was finally replaced with $150 \mu \mathrm{L}$ of $0.1 \%$ dimethyl sulfoxide (DMSO), agitated at 50 oscillations $/ \mathrm{min}$ for $10 \mathrm{~min}$ to completely dissolve the resultant formazan crystals. The absorbance of the samples was read in a microplate reader at 563 $\mathrm{nm}$. The assay was performed in triplicates. Cell viability (V) was calculated as shown in Eq 1.

$V(\%)=(A s / A c) 100$

where As and Ac are the absorbance of experimental and control samples, respectively.

\section{Western blotting}

HT-29 cells $\left(5 \times 10^{8} / L\right)$ were incubated with TCPB $(1.0-6.0 \mu \mathrm{M})$ for $72 \mathrm{~h}$. The cells were then washed twice with phosphate-buffered saline (PBS) and $250 \mu \mathrm{L}$ of ice-cold radioimmunoprecipitation assay buffer (RIPA) containing protease and phosphatase inhibitor 
was used to lyse them. The resultant lysate was centrifuged at $14,000 \mathrm{rpm}$ for $20 \mathrm{~min}$ at $4{ }^{\circ} \mathrm{C}$, and the protein concentration of the supernatant was determined using Bradford method. A portion of total cell protein $(10 \mu \mathrm{g})$ from each sample was separated on $8 \%$ sodium dodecyl sulphate (SDS)-polyacrylamide gel electrophoresis and transferred to a fixed polyvinylidene fluoride membrane at $110 \mathrm{~V}$ and $90{ }^{\circ} \mathrm{C}$ for $120 \mathrm{~min}$. Subsequently, non-fat milk powder $(5 \%)$ in Trisbuffered saline containing $0.2 \%$ Tween-20 (TBST) was added with gentle shaking at $37{ }^{\circ} \mathrm{C}$ and incubated to block non-specific binding of the blot.

Incubation of the blots was performed overnight at $4{ }^{\circ} \mathrm{C}$ with primary antibodies of rabbit polyclonal anti- Akt, p-Akt, bcl-2, bax, p53, cyt-c, procasapse-3, procaspase-9, PARP1 and $\beta$-actin, each at a dilution of 1 to 1000 . Then, the membrane was washed thrice with PBS and further incubated with horseradish peroxidaseconjugated goat anti-rabbit $\lg G$ secondary antibody for $1 \mathrm{~h}$ at room temperature.

The blot was developed using an X-ray film. Grayscale analysis of the bands was performed using Enhanced chemiluminescence (ECL). Respective protein expression levels were normalized to that of $\beta$-actin which was used as a standard.

\section{Cell cycle analysis}

The effect of TCPB on cell cycle distribution in HT-29 cells was determined using a flow cytometer. The HT-29 cells treated with varied concentrations of TCPB $(1.0-6.0 \mu \mathrm{M})$ were seeded into 6-well plates and incubated for $72 \mathrm{~h}$. The cells were then washed with PBS, and fixed with $70 \%$ ethyl alcohol at $4^{\circ} \mathrm{C}$ overnight. Tris-hydrochloride buffer $(\mathrm{pH} 7.5)$ containing $1 \%$ RNase A was then added to the plates. The cells were subsequently stained with propidium iodide and injected into the flow cytometer for analysis.

\section{Apoptosis assay}

The cells were seeded at a density of $2.5 \times 10^{6}$ cells/well into 6-well plates and cultured for $24 \mathrm{~h}$. Then, TCPB $(1.0-6.0 \mu \mathrm{M})$ was added to the medium and incubated for another $72 \mathrm{~h}$, and thereafter washed with PBS, and thoroughly mixed with $300 \mu \mathrm{L}$ binding buffer. The cells were then stained with $5 \mu \mathrm{L}$ each of annexin $\mathrm{V}$-fluorescein isothiocyanate and propidium iodide within $25 \mathrm{~min}$ at room temperature in the dark. Cell apoptosis was assessed using a flow cytometer fitted with argon laser operated at 485 $\mathrm{nm}$.

\section{Determination of ROS}

The levels of ROS in HT-29 cells were determined using DCFH-DA assay. The cells treated with TCPB $(1.0-6.0 \mu \mathrm{M})$ were washed with PBS after an initial incubation for $72 \mathrm{~h}$. Then, $10 \mu \mathrm{M}$ solution of DCFH-DA was added to the plates and incubated for another $35 \mathrm{~min}$ at $37^{\circ} \mathrm{C}$. Thereafter, the cells were washed with PBS and injected into the flow cytometer for analysis.

\section{Statistical analysis}

Data are expressed as mean $\pm S D$, and statistical analysis was performed using SPSS (20.0). Groups were compared using Student $t$-test. Values of $p<0.05$ were considered statistically significant.

\section{RESULTS}

\section{Effect of TCPB on the viability of DLD-1 and HT-29 cells}

As shown in Figure 1, treatment of DLD-1 and HT29 cells with TCPB significantly and dosedependently reduced their viability $(p<0.05)$. The viability of DLD-1 cells decreased progressively from 98 to $25 \%$, while the viability of HT-29 cells decreased from 99 to $19 \%$.

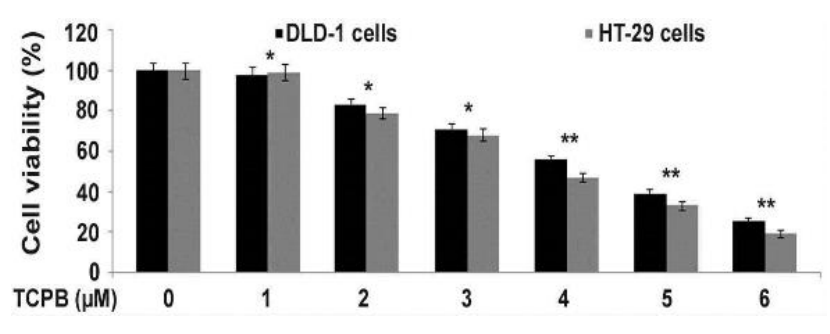

Figure 1: Effect of TCPB on DLD-1 and HT-29 cell viability. Incubation of cells with $1-6 \mu \mathrm{M}$ of TCPB for 72 $h$ was followed by MTT assay. The values shown are mean \pm SD of the triplicate experiments; ${ }^{*} p<0.05$ and ${ }^{* *} p<0.01$ versus untreated DLD- 1 and HT-29 cells

\section{Effect of TCPB on HT-29 cells apoptosis}

Treatment of HT-29 cells with TCPB significantly and dose-dependently increased the number of apoptotic cells $(p<0.05)$. The population of apoptotic cells increased from 11.16 to $68.34 \%$ (Figure 2).

\section{Effect of TCPB on cell cycle progression in HT-29 cells}

Treatment of HT-29 cells with TCPB significantly increased cell population in the G0/G1 phase, and significantly reduced cell proportion in S and G2/M phases $(p<0.05)$. In control cultures, the popula 

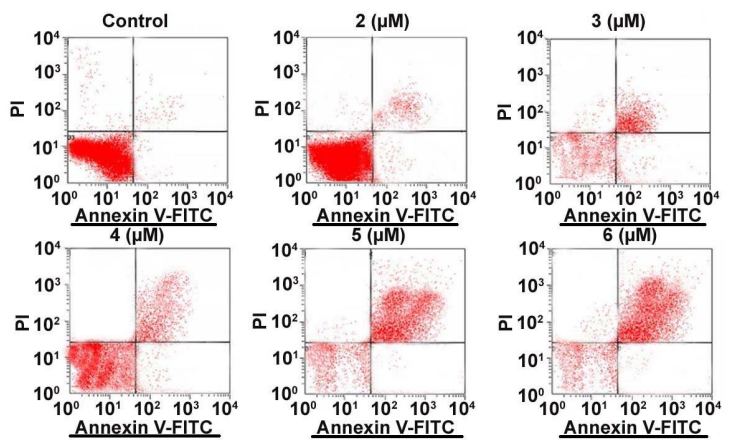

Figure 2: Effect of TCPB on HT-29 cell apoptosis. (A) HT-29 cells after exposure to 2, 3, 4, 5 and $6 \mu \mathrm{M}$ of TCPB for $72 \mathrm{~h}$ were analysed by flow cytometry for apoptosis. (B) The population of apoptotic HT-29 cells after $72 \mathrm{~h}$ of exposure to various concentrations of TCPB; ${ }^{*} p<0.05$ and ${ }^{* *} p<0.02$ versus untreated HT-29 cells

tion of cells in G0/G1 phase was progressively increased from 52.63 to $68.33 \%$ on treatment with varied concentrations of TCPB. Treatment with TCPB decreased HT-29 cell population in G2/M phase from 23.67 to $17.36 \%$. These results are shown in Figure 3.

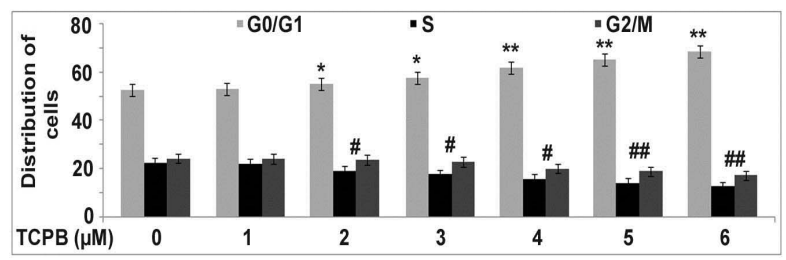

Figure 3: Effect of TCPB on cell cycle distribution in HT-29 cells; $p<0.05$ and $p<0.01$, when compared with control cells

\section{Effect of TCPB on the expression levels of apoptotic proteins in HT-29 cells}

Treatment of HT-29 cells with TCPB significantly and dose-dependently upregulated the expressions of caspase- 3 and bax, and significantly and dose-dependently downregulated the expression of bcl-2 $(p<0.05$; Figure 4).

\section{Effect of TCPB on levels of expression of mitochondrial proteins in HT-29 cells}

Treatment of HT-29 cells with TCPB significantly and dose-dependently upregulated the expressions of p53, cyt-c, procaspase-3, and procaspase- $9(p<0.05)$. However, it significantly and dose-dependently down-regulated the expression of p-Akt $(p<0.05)$, but did not significantly alter the level of expression of Akt in HT-29 cells $(p>0.05)$. However, it promoted the cleavage of PARP1 $(p<0.05)$. These results are shown in Figure 5.

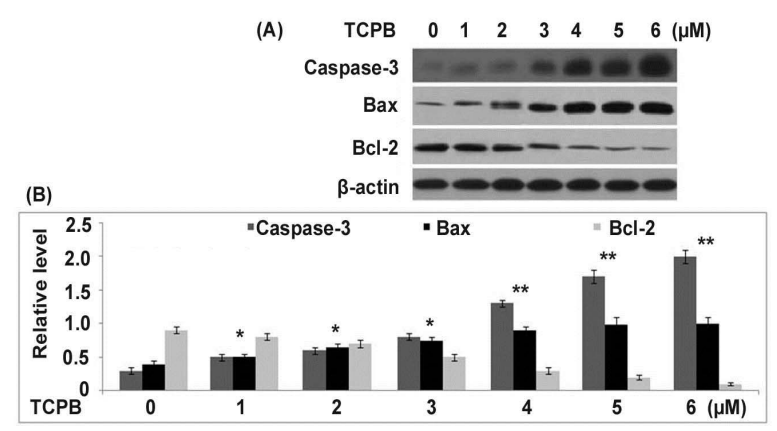

Figure 4: Effect of TCPB on the expression levels of apoptotic proteins in HT-29 cells treated with TCPB. (A): Expressions of apoptotic proteins as determined using Western blotting; and (B): Densitometric analysis of Western blot; $p<0.05$ and ${ }^{* *} p<0.01$, when compared with control cells

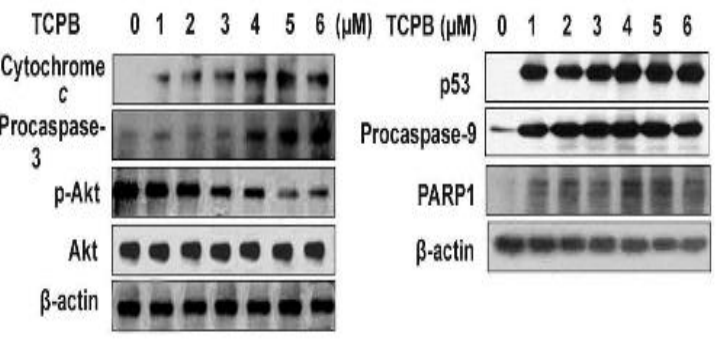

Figure 5: Levels of expression of mitochondrial proteins in HT-29 cells treated with TCPB

\section{Effect of TCPB on ROS production in HT-29 cells}

As shown in Figure 6, treatment of HT-29 cells with TCPB significantly and dose-dependently increased the levels of ROS $(p<0.05)$.

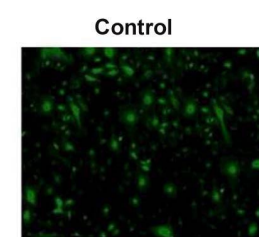

$4(\mu \mathrm{M})$

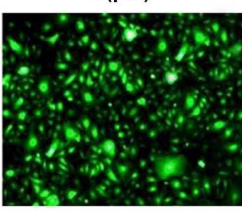

$2(\mu \mathrm{M})$

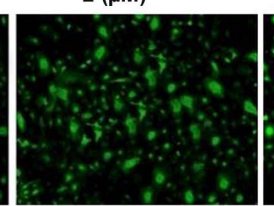

$5(\mu \mathrm{M})$

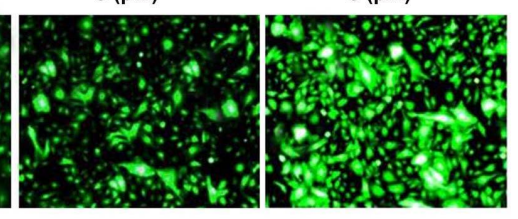

Figure 6: ROS levels in HT-29 cells treated with TCPB

\section{DISCUSSION}

Colorectal cancer (CRC), also known as bowel or colon cancer, is cancer of the colon or rectum. Its symptoms depend on the size and location of the cancer, and they include changes in bowel habits and stool consistency, presence of blood in the stool (haematochezia) and abdominal 
discomfort. The present study investigated the apoptotic effect of TCPB on CRC cells, and the underlying mechanism.

The results of MTT assay showed that treatment of DLD-1 and HT-29 cells with TCPB significantly and dose-dependently reduced their viability. Moreover, TCPB promoted apoptosis and ROS generation, and upregulated the expressions of pro-apoptotic proteins, while down-regulating the expression of anti-apoptotic protein in CRC cells. Generally, mammalian cells undergo apoptosis via the mitochondrial pathway [13]. Most anticancer drugs inhibit proliferation of cancer cells via activation of caspases and alteration in established potential of the mitochondrial membrane [13]. The disruption of mitochondrial membrane potential is as indication of early stage of cell apoptosis which is characterized by release of cytochrome $\mathrm{c}$ from the mitochondria $[14,15]$. Efflux of cytochrome $c$ from the mitochondria is accompanied by increased expression of caspases 3 and $9[14,15]$. The results of this study suggest that TCPB may trigger caspase-3 activation in HT-29 cells.

In this study, treatment of HT-29 cells with TCPB significantly arrested cell cycle progression to $S$ phase (cell cycle arrest at G0/G1 phase), an indication that TCPB may reduce viability of HT29 cells by induction of apoptosis in these cells. Treatment of HT-29 cells with TCPB significantly and dose-dependently upregulated the expressions of caspase- 3 and bax, and significantly and dose-dependently downregulated the expression of bcl-2.

Treatment of HT-29 cells with TCPB significantly and dose-dependently upregulated the expressions of p53, cyt-c, procaspase- 3 , and procaspase-9. However, it significantly and dosedependently down-regulated the expression of $p$ Akt, but did not significantly alter the level of expression of Akt in HT-29 cells. However, it promoted the cleavage of PARP1.

The activation of Akt plays a vital role in inhibiting cell apoptosis [16]. It has been reported that phosphorylation of Akt is closely associated with the inhibition of caspase-8 activity through increased expression of FLICE inhibitory protein [17]. Overexpression of bax protein plays is vital in cellular apoptosis [18]. In cells, bcl-2 is highly expressed at sites of ROS production such as mitochondria and nuclear membranes [19]. It promotes the scavenging of ROS, thereby preventing apoptosis [19]. Anticancer drugs that increase bax/bcl-2 protein ratio have been shown to exert apoptosis-inducing potential [20]. It is likely that TCPB induces apoptosis in CRC cells by increasing the bax/bcl-2 ratio. Excess production of ROS leads to oxidative damage of mitochondria and this serves as an apoptotic signal [21]. In this study, treatment of HT-29 cells with TCPB significantly and dose-dependently increased the levels of ROS, an indication that TCPB may promote ROS production in HT-29 cells.

\section{CONCLUSION}

The results obtained in this study suggest that TCPB exerts apoptotic effect on CRC cells via activation of mitochondria-dependent pathway. Thus, this compound has a potential for further development as an agent for the treatment of colorectal cancer in humans.

\section{DECLARATIONS}

\section{Conflict of interest}

No conflict of interest is associated with this work.

\section{Contribution of authors}

We declare that this work was done by the authors named in this article and all liabilities pertaining to claims relating to the content of this article will be borne by the authors. Kuan $\mathrm{Hu}$ designed the study and wrote the paper. Zhongfu Xiao, Ke Zhang and Yun Huang performed the experimental work, Yufan Zhou carried out the literature study and compiled the data. Zhongfu Xiao, Ke Zhang and Yun Huang performed literature survey, analyzed the data and compiled the data. The research article was thoroughly read by all the authors before commination for the consideration of publication.

\section{Open Access}

This is an Open Access article that uses a funding model which does not charge readers or their institutions for access and distributed under the terms of the Creative Commons Attribution License (http://creativecommons.org/licenses/by/ 4.0) and the Budapest Open Access Initiative (http://www.budapestopenaccessinitiative.org/rea d), which permit unrestricted use, distribution, and reproduction in any medium, provided the original work is properly credited.

\section{REFERENCES}

1. Linsalata M, Russo F. Nutritional factors and polyamine metabolism in colorectal cancer. Nutri 2008; 24: 302- 
389.

2. Volate SR, Davenport DM, Muga J, Wargovich MJ. Modulation of aberrant crypt foci and apoptosis by dietary herbal supplements (quercetin, curcumin, silymarin, ginseng and rutin). Carcinogenesis 2005; 26. 1450-1456.

3. Park HJ, Kim MJ, Ha E, Chung JH. Apoptotic effect of hesperidin through caspase 3 activation in human colon cancer cells, SUN-C4. Phytomed 2008; 15: 147-151.

4. Fang XL. Study the curative effect of advanced stage colon carcinoma treated by L-OHP combined with 5FU/CF. Chin J Clin Ration Drug Use 2009; 2: 8-9 (In Chinese).

5. Sileri P, Dugo S, Benavoli D, Stolfi VM, Palmieri G, Mele A, Gaspari AL. Metachronous splenic metastasis from colonic carcinoma five years after surgery: a case report and literature review. South Med J 2009; 102: 733-735.

6. Kaufmann $\mathrm{SH}$, Hengartner MO. Programmed cell death: alive and well in the new millennium. Trends Cell Biol 2001; 11: 526-534.

7. Reed JC. Apoptosis-regulating proteins as targets for drug discovery. Trends Mol Med 2001; 7: 314-319.

8. Earnshaw WC, Martins LM, Kaufmann SH. Mammalian caspases: structure, activation, substrates, and functions during apoptosis. Annu Rev Biochem 1999; 68: 383-424.

9. Sun XM, MacFarlane M, Zhuang J, Wolf BB, Green DR, Cohen GM. Distinct caspase cascades are initiated in receptor-mediated and chemical-induced apoptosis. J Biol Chem 1999; 274: 5053-5060.

10. Thompson CB. Apoptosis in the pathogenesis and treatment of disease. Sci 1995; 267: 1456-1462.

11. Lee KH. Anticancer drug design based on plant-derived natural products. J Biomed Sci 1999; 6: 236-250.

12. Terao J. Dietary flavonoids as antioxidants. Forum Nutr 2009; 61: 87-94.

13. Ling YH, Liebes L, Zou Y, Perez-Soler R. Reactive oxygen species generation and mitochondrial dysfunction in the apoptotic response to Bortezomib, a novel proteasome inhibitor, in human $\mathrm{H} 460$ non-small cell lung cancer cells. Biol Chem 2003; 278: 3371433723.
14. Doi S, Soda H, Oka M, Tsurutani J, Kitazaki T, Nakamura Y, Fukuda M, Yamada Y, Kamihira S, Kohno S. The histone deacetylase inhibitor FR901228 induces caspase-dependent apoptosis via the mitochondrial pathway in small cell lung cancer cells. Mol Cancer Ther 2003; 3: 1397-1402.

15. Ogbourne SM, Suhrbier A, Jones B, Cozzi SJ, Boyle GM, Morris M, McAlpine D, Johns J, Scott TM, Sutherland $K P$, Gardner JM, Le TT, Lenarczyk A, Aylward JH, Parsons PG. Antitumor activity of 3-ingenylangelate: plasma membrane and mitochondrial disruption and necrotic cell death. Cancer Res 2004; 64: 2833-2839.

16. Franke TF, Hornik CP, Segev L, Shostak GA, Sugimoto C. PI3K/Akt and apoptosis: size matters. Oncogene 2003; 22: 8983-8998.

17. Panka DJ, Mano T, Suhara T, Walsh K, Mier JW. Phosphatidylinositol 3-kinase/Akt activity regulates $c$ FLIP expression in tumor cells. J Biol Chem 2001; 276: 6893-6896.

18. Hayward RL, Macpherson JS, Cummings J, Monia BP, Smyth JF, Jodrell DI. Enhanced oxaliplatin-induced apoptosis following antisense $\mathrm{BCl}-\mathrm{xl}$ down-regulation is p53 and Bax dependent: genetic evidence for specificity of the antisense effect. Mol Cancer Ther 2004; 3: 169178.

19. Sinicrope FA, Penington RC. Sulindac sulfide-induced apoptosis is enhanced by a small-molecule Bcl-2 inhibitor and by TRAIL in human colon cancer cells over-expressing Bcl-2. Mol Cancer Ther 2005; 4: 14751483.

20. Childs AC, Phaneuf SL, Dirks AJ, Phillips T, Leeuwenburgh $C$. Doxorubicin treatment in vivo causes cytochrome $C$ release and cardiomyocyte apoptosis, as well as increased mitochondrial efficiency, superoxide dismutase activity, and Bcl-2/Bax ratio. Cancer Res 2002; 62: 4592-4598.

21. Batra S, Reynolds CP, Maurer BJ. Fenretinide cytotoxicity for Ewing's sarcoma and primitive neuroectodermal tumor cell lines is decreased by hypoxia and synergistically enhanced by ceramide modulators. Cancer Res 2004; 64: 5415-5424. 